\title{
A rare case of ovarian granulosa cell tumor in Turkey (Meleagris gallopavo)
}

\author{
B. P. Kamdi, P. M. Sonkusale, S. W. Raut, R. K. Pande, A. G. Bhandarkar and N. \\ V. Kurkure \\ Department of Veterinary Pathology, Nagpur Veterinary College, Nagpur, MAFSU Nagpur, India. \\ Author for correspondence: Bhupesh Kamdi, Department of veterinary Pathology, Nagpur Veterinary College, \\ Nagpur.
}

Abstract: In the present study ovarian granulosa cell tumour was diagnosed during necropsy of a turkey. Grossly the ovary was enlarged appeared nodular, friable and lobulated. Microscopically, the type cells were identified as granulosa cells. The tumour showed folliculoid pattern in larger masses of cells along with severe hemorrhages.

Key words: Granulosa cells, Turkey, Call-Exner bodies

\section{Introduction}

Birds are susceptible to many neoplastic conditions including Marek's disease, Lymphoid leucosis, adenoma, hepatoma, haemangioma, fibroma, nephroblastoma, chondroma, granulosa cell tumor, endothelioma and osteofibroma (Swathi and Reddy, 2012). Amongst birds ovarian tumors are rare. Hens, turkeys, budgerigars, guinea fowl and other avian species, older than one year of age are mostly susceptible for the occurrence of ovarian tumors. In India, the reports on ovarian tumors in birds are very rare. Ovarian granulosa cell tumor was first reported in a Rhode Island Red hen(Shukla and Iyer, 1960). Compared to other ovarian tumors, granulosa cell tumor is a very rare neoplastic condition in most species of poultry. An ovarian granulosa cell tumorin turkey is being reported in present communication.

\section{Materials And Methods}

A three year old female turkey carcass from the college poultry farm was brought to Department of Veterinary Pathology, Nagpur Veterinary College, Nagpur for necropsy. Detailhistory,clinical signs and gross lesions were noted and photographed. For histopathological investigations, affected organs were collected in the neutral buffered formalin. Fixed tissues were processed following standard procedure according to the Luna (1960) and stained with hematoxaline and eosin stain.

\section{Results}

The clinical history was reduced feed intake, lethargy and ascites. General condition of the carcass was emaciated and the abdomen was distended and pendulous. On post mortem, the ovary was found to be very much enlarged and lobulated filling almost the entire abdominal cavity (Fig.1). Numerous small nodules and follicles of varying sizes giving nodular appearance to the tumorwere observed. The growth was yellowish white in colour with distinct lobulations. The cut surfaces of the growth including those of the nodular masses appeared firm and solid without any cavities. The follicles were of different sizes and shapes with an extremely friable consistency. Some follicles appeared congested and necrotic. The visceral organs were compressed by the tumor mass. Intestine was empty as well as liver, heart, spleen, lung and kidneys were severely congested. Abdominal cavity contained serosanguinous fluid. The lesions in the present case were similar to those described by earlier workers in domestic fowls (Shukla and Iyer, 1960; Sharma,1990).

Histopathologicaly, it consisted of irregular accumulation of cellular masses separated by moderately vascularized connective tissue stroma. The type cells were indistinguishable from the granulosa cells of normalgraffian follicles. There were no maturing follicles in the rest of the ovaryhowever large numbers of individual follicles, without oocytes, were scattered under the germinal epithelium. The cells were densely packed, eosinophilic, polyhedral to fusiform in shape, uniformsized, possessed large central nucleus and considerableamount of cytoplasm (Fig.2). Intracytoplasmic vacuoles were prominent in a few cells. The tumor mass showedtubular arrangements and rosettes were formed byclusters of cells radiating out from small central lumina (Fig.3). Fibrous connective tissue forming trabeculae like structures were also seen which replaces the parenchyma at places. 
Multiple focal areasof hemorrhages were scattered throughout the tumormass probably due to the rupture of capillaries. The cells were found to be detached from thebasement connective tissue and lying in the lumen incertain other places, due to necrotic changes. Pale acidophilic, tiny foci of necrosis were observed in the large masses of cells which resembled the structures called 'Call-Exner bodies' (Meuten, 2002; Reece, 2003). The tumor in the present case showed a tubular pattern in general but folliculoid pattern in larger masses of cells.

\section{Discussion}

Granulosa cell tumor is the most common sex cord stromal tumor found in the domestic animals and poultry birds, however information regarding its occurrence in the turkey is lacking, therefore present effort are made to report the occurrence of tumor in the turkey. Gross findings reveled in the present study were in agreement with earlier findings (Fredrickson, 1987, Swathi et al., 2012,).

Histopathological lesions includes presence of 'Call-Exner' bodies in the section confirms the granulose cell tumor(Awadhiya and Jain, 1967; Meuton, 2002).These bodies were observed due to spaces formed by necrosis and liquefaction of small foci of granulosa cells and such spaces contained acidophilic fluid with a few degenerated granulosa cells. The histological pattern of granulosa cell tumor revealing such structures as rosettes or bodies resembling 'Call-Exner bodies' in masses of cells is known as folliculoid pattern and is considered as a typical diagnostic feature. Variability in the histological pattern in different regions of the tumor is another interesting feature of the granulose cell tumor (Awadhiya and Jain, 1967).

\section{Conclusion}

Gross and histological observation confirms the granulose cell tumor. As granulosa cell tumor is rare in turkey author thought to put the same on record.

\section{Reference}

[1] R. P. Awadhiya, and S. K. Jain, Studies on the pathology of neoplasms in animals,Indian Veterinary. Journa,44, 1967, 917-919.

[2] D. J. Meuten, (Tumors in domestic animals fourth edition, Iowa state press. 55, 2002)

[3] R. L. Reece, Other tumours of unknown etiology. In: Saif YM, Barnes HJ, Glisson JR, Fadly AM, McDougald, L. R. and Swayne, D. E. (Edn).Dis. Poultry. (11 ${ }^{\text {th }}$ Edn. Blackwell Publishing Co. Pvt. Ltd. 542-545, 2003)

[4] R. N. Sharma, Ovarian tumour and teratoma in poultry. Indian J. Vet.Pathol. 14, 1990, 79-81.

[5] S. D. Sharma, and P. B. Kuppuswamy, Granulosa cell tumour in poultry. Indian Vet. J. 47, 1970, 630-632.

[6] R.R. Shukla, and P. K. R. Iyer,)A rare ovarian granulosa cell tumour in a hen. Indian Vet. J.,

[7] B. Swathi, A.A. Kumar, and M.R. Reddy, Histological and molecular diagnosis of poultry tumours. Indian J. Vet.Pathol.36(1), 2012, 4148.

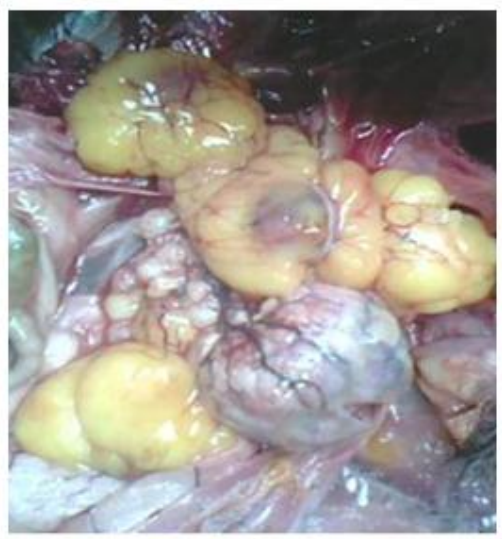

Figure 1:Highly enlarged nodular and lobulated ovarian tumor

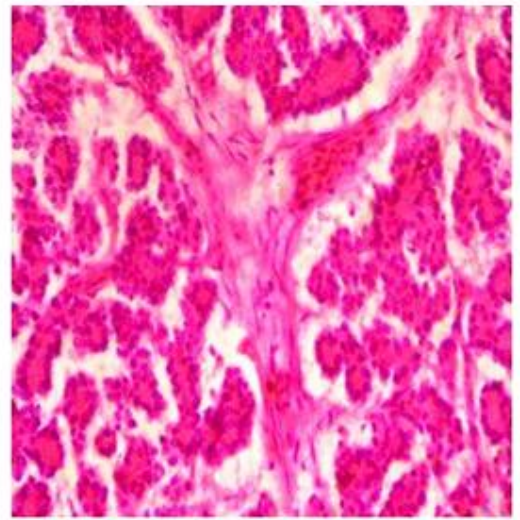

Figure 2: Densely packed polyhedral to fusiform shaped neoplastic cells with large central nucleus. H\& E x 400X.

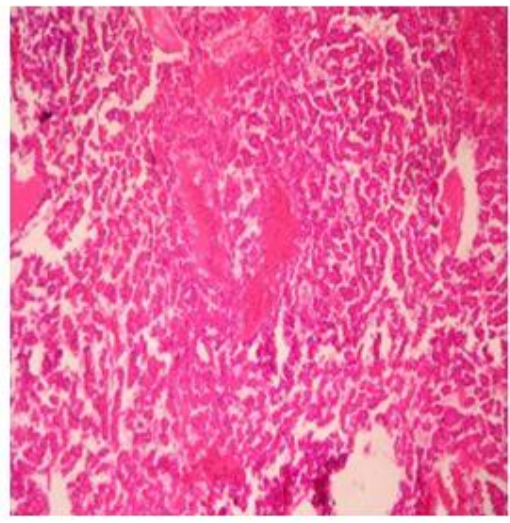

Figure 3: Tubular arrangement of tumor mass with hemorrhages. $\mathrm{H} \& \mathrm{E} \times 100$. 